\title{
Coronary Artery Disease prevalence in Heart Failure with Re- duced Ejection Fraction
}

\author{
Shaneez Najmy ${ }^{1}$, Rajan Paudel ${ }^{1}$, Ajay Adhikari ${ }^{1}$, Reeju Manandhar ${ }^{2}$, Chandra Mani Adhikari ${ }^{2}$, Ram \\ Kishor Sah', Rabi Malla², Arun Maskey², Deewakar Sharma², Sujeeb Rajbhandari²
}

${ }^{1}$ National Academy of Medical Sciences, Kathmandu, Nepal

${ }^{2}$ Shahid Gangalal National Heart Centre, Bansbari, Kathmandu

Corresponding Author: Shaneez Najmy

Department of Cardiology National Academy of Medical Sciences, Kathmandu, Nepal

E-mail: m shaneez@hotmail.com

ORCID ID NO: 0000-0001-5566-2915

Cite this article as: Najmy S., Paudel R., Adhikari A., et al. Coronary Artery Disease prevalence in Heart Failure with Reduced Ejection Fraction. Nepalese Heart Journal 2019; Vol 16 (2), 29-34

Submission date: $3^{\text {rd }}$ July 2019

Accepted date: $18^{\text {th }}$ October 2019

\section{Abstract}

Background and Aims: Even though heart failure (HF) is a major global health problem, studies on the prevalence and etiology of HF in Nepal are scant. Coronary artery disease (CAD) has been reported to be the etiology in $18 \%$ of HF presentations to the emergency department of a tertiary cardiac center in Nepal ${ }^{1}$. Present study evaluated the prevalence and characteristics of CAD in HF with reduced ejection fraction (HFrEF) with coronary angiography (CAG).

Methods: In a prospective, observational study, conducted from June 2018 to May 2019, 95 patients with HFrEF undergoing CAG, at Shahid Gangalal National Heart Centre, were evaluated.

Results: The mean age of the patients was $62.7 \pm 10.1$ years, with $67 \%$ males. Obstructive CAD was present in $31(33 \%)$ with $48 \%, 39 \%$ and $13 \%$ having triple (TVD), single (SVD) and double vessel disease (DVD) respectively. Age $\geq 65$ years, smokers, dyslipidemia, obesity, angina, indexed left ventricular end diastolic volume (iEDV), indexed LV systolic diameter (iLVIDs) and regional wall motion abnormality (RWMA) on echocardiography were predictors of CAD, among only which, smoking was the independent predictor of CAD.

Conclusion: Our results suggest a lower prevalence of CAD in HFrEF than previously reported from developed countries, which may be due to a systematic angiography approach and exclusion of previous coronary events. We encourage clinicians to aggressively identify this co-morbidity as it has important treatment and prognostic implementations.

Keywords: Coronary angiography Coronary artery disease; Heart failure with reduced ejection fraction; Prevalence; Predictors.

DOI: https://doi.org/10.3126/njh.v16i2.26314

\section{Introduction}

Despite advances in cardiovascular diseases, chronic heart failure (HF) is a category, which the prevalence, incidence, hospitalization rate, total burden of mortality, and costs have increased in the past 2-3 decades ${ }^{2}$. Even though HF is a major global health problem, the data from developing countries are sparse $e^{3}$. The effect of the epidemiologic transition varies not only among countries but also among regions, communities or ethnicities in the same country, making it difficult to generalize evidence obtained not only from Western countries but also from Asian countries ${ }^{4}$. Coronary artery disease (CAD) accounts for about two-thirds of cases of heart failure with reduced ejection fraction $(\mathrm{HFrEF})^{5}$. Angina symptoms and conventional cardiovascular (CV) risk factors are not adequate to establish an ischemic etiology and according to recommendations, coronary angiography $(\mathrm{CAG})$ is the gold standard ${ }^{5,6}$. The angiographic approach for detecting CAD in HFrEF with or without known CAD has not been well studied, and some authors recommend routine $\mathrm{CAG}^{7}$. CAD is the leading cause of HFrEF, albeit with prevalence variations across various cohorts of populations and it is also an independent predictor of mortality in cardiomyopathy.

Demonstration of underlying etiology is cornerstone of $\mathrm{HF}$ diagnosis and virtually all patients with unexplained HF should be evaluated for the presence of CAD. Most patients with HF due

(a) Nepalese Heart Journal. Nepalese Heart Journal retain copyright and works is simultaneously licensed under Creative Commons Attribution License CC - By 4.0 that allows others to share the work with an acknowledge of the work's authorship and initial publication in this journal 
to ischemic cardiomyopathy have known coronary heart disease ${ }^{8}$. Occult disease is a not uncommon cause of dilated cardiomyopathy, accounting for approximately $7 \%$ of initially unexplained cases. Up to one-third of patients with non-ischemic cardiomyopathy have chest pain that may resemble angina or be atypical. Revascularization may be of benefit in the appreciable number of patients in whom hibernating myocardium or silent ischemia is in part responsible for the decline in myocardial function. There is a direct relationship between the severity of left ventricular dysfunction and the magnitude of benefit in HF with documented viable myocardium?. However, the mere presence of asymptomatic angiographic coronary artery disease in patients with dilated cardiomyopathy does not prove causality unless there is evidence of prior infarction or hibernating myocardium ${ }^{10,11}$.

Data regarding prevalence of heart disease in Nepal are sparse. Shrestha et $\mathrm{al}^{12}$ had described the profile of HF in the western regions and reported CAD as etiology in $29 \%$ of $274 \mathrm{HF}$ patients. Another study from Bharatpur with $255 \mathrm{HF}$ admissions to a tertiary cardiac center reported $36.5 \% \mathrm{CAD}$ as the etiology of $\mathrm{HF}^{13}$. In both studies, the commonest cause of HF was CAD.

Therefore, we planned to conduct this study to evaluate the prevalence of significant $\mathrm{CAD}$ using angiographic approach in patients with HFrEF without coronary events or significant valvular heart disease.

\section{Methods}

This was a hospital based, cross-sectional observational study carried out in Shahid Gangalal National Heart Centre, Kathmandu, Nepal from June 2018 to June 2019.

The study protocol conformed to the ethical guidelines of the declaration of Helsinki and was approved by the Institutional Review Board and after informed consent, 95 patients with Clinical diagnosis of HF, diagnosed by the Framingham Congestive Heart Failure criteria $^{14}$, with $\mathrm{EF} \leq 40 \%$ undergoing CAG were enrolled in the study (figure-1) after excluding:

- Moderate to severe valvular heart disease

- Documented MI or Previous coronary revascularization

- Myocarditis

- Diagnosed Non-ischemic cardiomyopathy

- Angiographically proven CAD

The clinical data recorded included the risk factors for CAD and the symptomatology of the patients. Echocardiographic assessment and chamber quantification was done with a Philips ultrasound system as per American Society of Echocardiography (ASE) recommendations ${ }^{15}$. Measurements of LV volumes and ejection fraction were done by manual tracing of an endocardial border from apical 4- and 2-chamber views using the disk summation method.

Arteriograms of the right and left coronary arteries were performed and the best projection, representing stenosis of the lesion with progression, were selected and examined for percentage diameter stenosis by quantitative coronary angiographic analysis by use of a cardiovascular measurement system (Philips Medical Imaging Systems) in accordance with standard guidelines ${ }^{6}$. Coronary arteriograms were reviewed by the principal investigator and one independent observer experienced in angiographic interpretation and blinded to the clinical data. The degree of coronary artery obstruction were expressed as the $\%$ diameter stenosis, by comparing the diameter of the site of greatest narrowing (minimal lumen diameter) to an adjacent segment assumed to be free of disease. Lesion in an epicardial coronary artery was considered significant in $\geq 70 \%$ stenosis of the examined vessel or $\geq 50 \%$ of Left Main Coronary Artery (LMCA). Lesion severity was also classified as:

- Minimal / minor CAD: $<50 \%$ stenosis

- Moderate: $50-70 \%$ stenosis

- Significant: $\geq 70 \%$ stenosis

The outline of the study is shown in figure-1.

Figure 1: Outline of the study

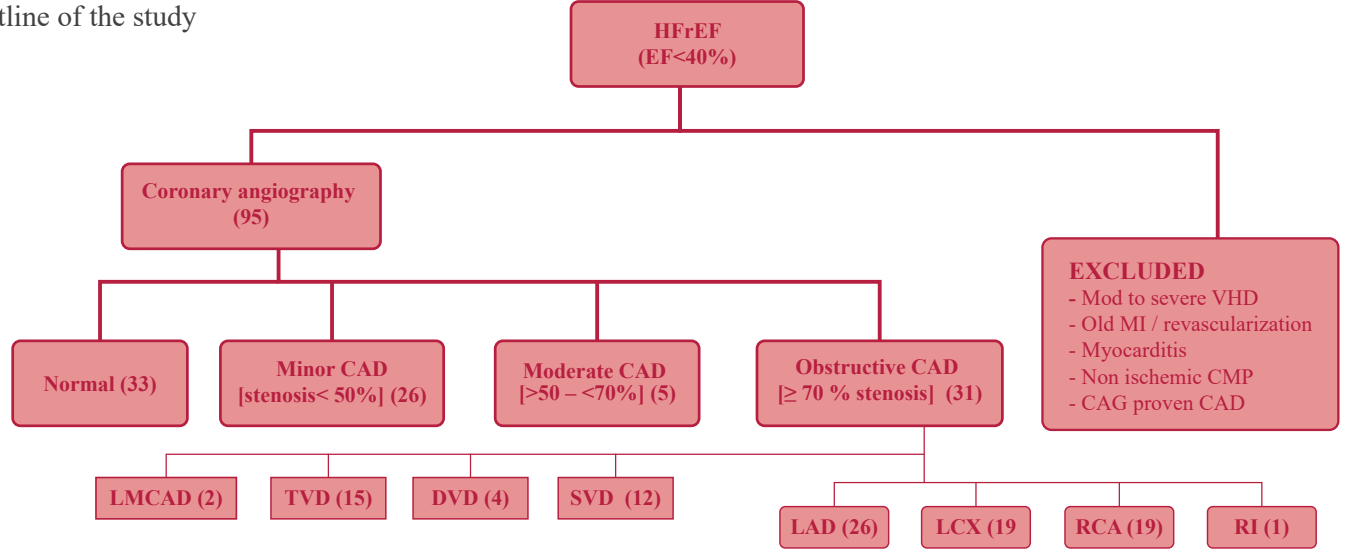

Statistical Analysis

Categorical variables were presented as proportions or percentages while continuous data were presented as mean \pm SD or median (IQR) depending on the normality of the data. In data analysis, 95\% confidence interval (CI), P-value, odds ratio (OR) were computed to conclude the result obtained. Continuous variables between the patients diagnosed with significant obstructive CAD and those who did not have significant obstructive CAD were analyzed using an independent samples t-test after assessing the normality of data. Categorical variables were analyzed using the $\chi 2$ test.
Multivariate logistic regression analysis was utilized to evaluate the independent variables and the presence or absence of significant obstructive CAD. A backward-selection technique was used to generate a multivariable logistic regression model to determine the independent predictors of CAD. The Hosmer and Lemeshow test were used to assess the fitness of the model ( $p=0.824$ and Nagelkerke $\mathrm{R}$ Square 0.42 ). Logistic regression analysis was used to evaluate the independent predictors of CAD.

Statistical significance in all tests was assumed at $p$-value of $<0.05$. All statistical analysis was done using the SPSS version 20. 
Tabel 1: Clinical and Demographic Characteristics of Patients with HFrEF According to Presence or Absence of Significant CAD

\begin{tabular}{|c|c|c|c|c|c|}
\hline & & \multirow{2}{*}{$\begin{array}{c}\text { Total } \\
(n=95)\end{array}$} & \multicolumn{2}{|c|}{ Obstructive CAD } & \multirow[t]{2}{*}{ p value } \\
\hline & & & Present $(n=31)$ & Absent $(n=64)$ & \\
\hline Male & & 64 & 23 & 41 & 0.227 \\
\hline Female & & 31 & 8 & 23 & \\
\hline \multirow[t]{2}{*}{ Age } & $<65$ years & 55 & 13 & 42 & 0.025 \\
\hline & $\geq 65$ years & 40 & 18 & 22 & \\
\hline Smokers & & 21 & 15 & 6 & $<0.001$ \\
\hline Hypertension & & 48 & 18 & 30 & 0.211 \\
\hline Diabetes & & 23 & 10 & 10 & 0.154 \\
\hline Dyslipidemia & & 17 & 10 & 7 & 0.014 \\
\hline Obesity & & 43 & 22 & 21 & $<0.001$ \\
\hline Angina $\geq$ FC 2 & & 49 & 27 & 22 & $<0.001$ \\
\hline Dyspnea $\geq$ FC 2 & & 86 & 29 & 57 & 0.429 \\
\hline $\mathrm{QRSD} \geq 150 \mathrm{~ms}$ & & 57 & 22 & 35 & 0.097 \\
\hline LVH & & 4 & 0 & 4 & 0.200 \\
\hline iLVIDd (mm/m2) & & 95 & $3.33 \pm 0.49$ & $3.51 \pm 0.45$ & 0.090 \\
\hline iLVIDs $\left(\mathrm{mm} / \mathrm{m}^{2}\right)$ & & 95 & $2.85 \pm 0.54$ & $2.55 \pm 0.58$ & 0.016 \\
\hline $\mathrm{iEDV}\left(\mathrm{ml} / \mathrm{m}^{2}\right)$ & & 95 & $91 \pm 16$ & $99 \pm 14$ & 0.010 \\
\hline $\mathrm{iEDS}\left(\mathrm{ml} / \mathrm{m}^{2}\right)$ & & 95 & $63 \pm 17$ & $67 \pm 16$ & 0.186 \\
\hline Mitral regurgitation & & 66 & 19 & 47 & 0.166 \\
\hline \multirow[t]{2}{*}{ LVEF \% } & $>30-\leq 40 \%$ & 53 & 16 & 37 & 0.362 \\
\hline & $\leq 30 \%$ & 42 & 15 & 27 & \\
\hline \multirow[t]{2}{*}{ Wall Motion: } & RWMA & 20 & 12 & 8 & 0.009 \\
\hline & Global LV hypokinesia & 51 & 14 & 37 & 0.174 \\
\hline
\end{tabular}

\section{Results}

Baseline characteristics are summarized in table -1 . The mean age of the patients was $62.7 \pm 10.1$ years, with $67 \%$ males. Patients with age $\geq 65$ years $(42 \%)$ were more likely to have significant CAD (p $=0.025$ ). Only $22 \%$ among the current cohort were smokers, $45 \%$ were obese (BMI $\geq 25 \mathrm{kgm}^{-2}$ ), while $51 \%$ were hypertensive, $24 \%$ had diabetes and $18 \%$ had dyslipidemia. Dyspnea was the most common clinical manifestation ( $92 \%$ ), while $52 \%$ had angina. Broad QRS complex with QRS duration $\geq 150 \mathrm{~ms}$ was noted in $60 \%$ of the patients and three patients had sustained ventricular tachycardia. On echocardiographic evaluation, only four (4\%) had left ventricular hypertrophy, while the mean indexed LV systolic diameter diastole (iLVIDd) and indexed LV systolic diameter systole (iLVIDs) were $3.45 \pm 0.42$ and $2.76 \pm 0.55 \mathrm{~mm} / \mathrm{m}^{2}$, respectively. The median indexed end diastolic volume (EDV) and end systole volume (ESV) were $94.8(86.2-102.9)$ and $60.8(54.3-74.3) \mathrm{ml} / \mathrm{m}^{2}$, respectively. Mitral regurgitation was observed in $69 \%$. The mean LVEF $32.1 \pm 7.8 \%$ with $53.7 \%$ having global LV wall hypokinesia and $21 \%$ had regional wall motion abnormality (RWMA). Among the 20 patients having RWMA, LAD territory was involved in $19(95 \%)$ while one patient had wall motion in RCA territory.
Prevalence and characteristics of CAD

Obstructive CAD ( $\geq 70$ coronary stenosis) was present in $31(33 \%)$ while $26(27 \%)$ had minor CAD with $<50 \%$ coronary stenosis and only five $(5 \%)$ had moderate stenosis of $\geq 50$ to $<70 \%$ stenosis [Figure -2]. Most common pattern of CAD was TVD (48\%), followed closely by SVD (39\%) [Figure - 3]. Among the coronary arteries LAD (40\%) was the most commonly diseased vessel [Figure -4].

Fig -2: Results of Coronary Angiography

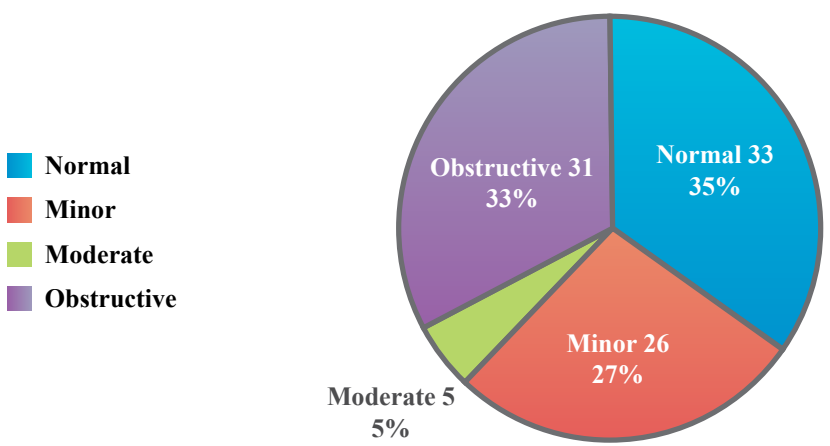


Fig -3: Number of Coronary Arteries Involved in Siginificant CAD with HFrEF.

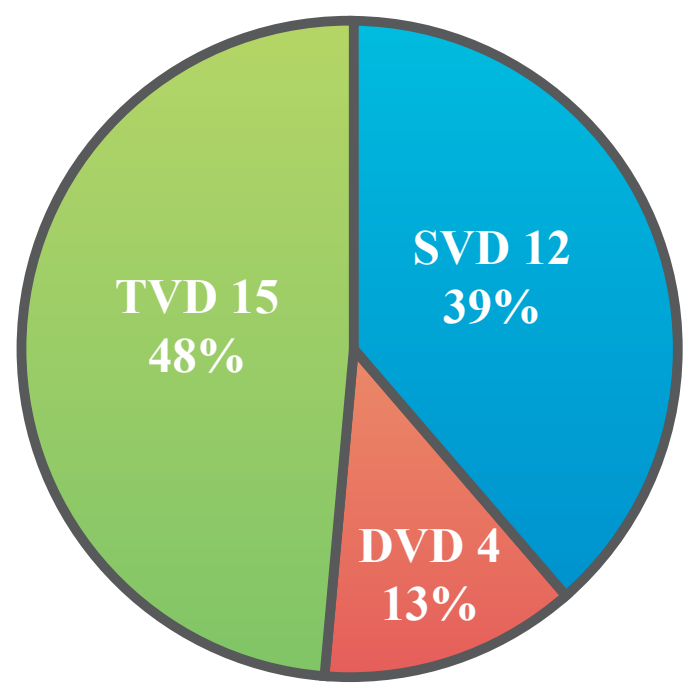

Fig - 4: Involvement of indivudual coronaries among significant CAD

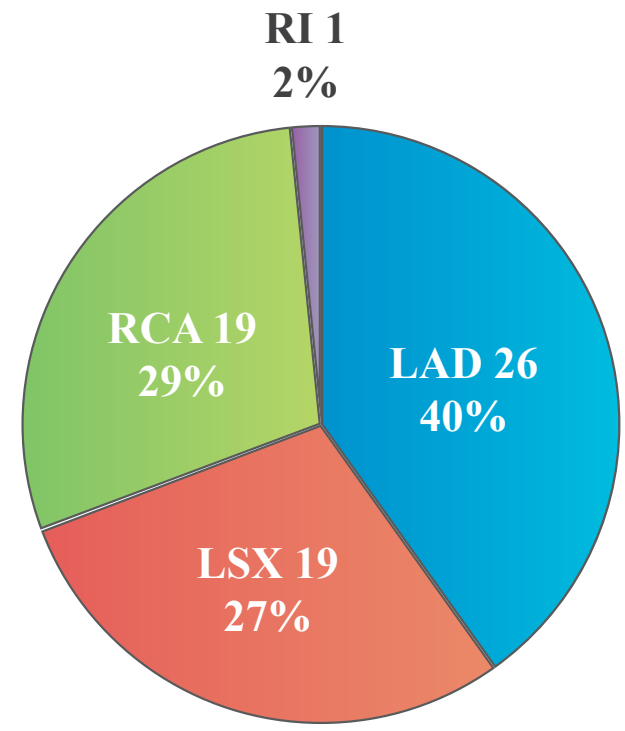

After comparison of clinical and laboratory features in patients with and without CAD clinical factors (Table 1) such as age $\geq 65$ years, smokers, dyslipidemia, obesity, angina and echocardiographic indicators iEDV, iLVIDs and RWMA were predictors of CAD. However on multivariate analysis, only smoking was the independent predictor of significant CAD (Table 2).
Table 2: Independent predictors of CAD in $\mathrm{HFrEF}$ - logistic regression analysis with $95 \% \mathrm{CI}$

\begin{tabular}{|c|c|c|c|c|c|c|}
\hline \multirow[t]{2}{*}{ Variable } & \multirow[t]{2}{*}{ B } & \multirow{2}{*}{$\begin{array}{l}\text { Wald } \\
x^{2}\end{array}$} & \multirow[t]{2}{*}{ P-value } & \multicolumn{2}{|c|}{$95 \%$ CI } & \multirow{2}{*}{$\begin{array}{l}\text { Odds } \\
\text { Ratio } \\
\text { (OR) }\end{array}$} \\
\hline & & & & Lower & Upper & \\
\hline $\begin{array}{l}\text { Age } \geq \\
65 y\end{array}$ & 1.012 & 3.052 & 0.081 & 0.884 & 8.569 & 2.752 \\
\hline Smoker & 1.716 & 5.997 & 0.014 & 1.408 & 21.946 & 5.560 \\
\hline Obesity & 0.860 & 1.848 & 0.174 & 0.684 & 8.168 & 2.363 \\
\hline $\begin{array}{l}\text { Dyslipi- } \\
\text { demia }\end{array}$ & 0078 & 1.707 & 0101 & 0.613 & 11.522 & 2.658 \\
\hline Angina & 1.397 & 1.953 & 0.162 & 0.570 & 28.700 & 4.044 \\
\hline RWMA & 0.745 & 1.154 & 0.283 & 0.541 & 8.208 & 2.107 \\
\hline iLVIDs & 0.303 & 0.160 & 0.689 & 0.307 & 5.964 & 1.354 \\
\hline iEDV & -0.048 & 3.407 & 0.065 & 0.953 & 1.003 & 0.953 \\
\hline $\begin{array}{l}>3 \text { risk } \\
\text { factors }\end{array}$ & -0.414 & 0.179 & 0.672 & 0.097 & 4.500 & 0.661 \\
\hline
\end{tabular}

\section{Discussion}

We performed a study analyzing the prevalence of CAD in patients with HFrEF undergoing CAG at our institute. Despite excluding patients with history or evidence of previous coronary events, the prevalence of CAD was $33 \%$. This is in contrast to the overall CAD prevalence in about two-thirds of cases of $\mathrm{HFrEF}^{5}$. But this higher prevalence reports are from series, which included patients with past coronary events like MI, Q waves on ECG and previous revascularization. Upon comparison with studies of CAD prevalence including cohorts with unexplained heart failure, our prevalence figures are similar ${ }^{16}$. Some publications also used a coronary stenosis of $\geq 50 \%$ to define significant $\mathrm{CAD}$, which would explain a higher prevalence of CAD. Our prevalence also closely matches the descriptive studies from Nepal ${ }^{12,13}$ suggesting one third of HFrEF are likely ischemic in our population. In clinical practice, systematic coronary angiography is not always possible in all patients admitted for heart failure, but the potential survival benefit of revascularization ${ }^{7}$ 17,18 , justifies that aggressive management of heart failure even in the elderly patients may be similar to the current approach for the treatment of aortic stenosis ${ }^{19}$. As previously demonstrated the use of angiography during the index hospitalization after admission for heart failure would allow CAD identification in a higher proportion of patients than after discharge ${ }^{20}$.

In clinical practice it is challenging for all patients with systolic $\mathrm{HF}$ of unclear etiology to undergo coronary angiography, hence we sought to derive clinical or echocardiographic predictors to suggest CAD as a cause of systolic HF. In our study CAD was significantly more common in patients with age $\geq 65$ years, smokers, dyslipidemia, obesity and had angina. The echocardiographic predictors were iEDV, iLVIDs and regional wall motion abnormality (RWMA). With these predictors, we sought to derive and validate a clinical prediction rule to rule in $\mathrm{CAD}$ which showed that having $>3$ risk factors is associated with ischemic cause for HF (figures - 5, 6, 7) with a sensitivity of $93 \%$ and specificity of $63 \%$. However, when multivariate analysis was done only smoking was the independent risk predictor of CAD (figure -8 ). This may be due to a small sample size in our study and hence, a larger study is likely to deliver us a better prediction model. 
Fig -5: Affect of no of Riks Factors on CAD Prevalence

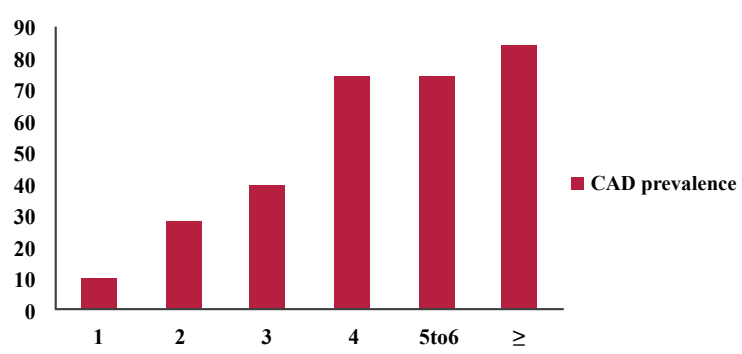

Fig -6: ROC Curve for Risk Factors $>3$ for Predicting CAD

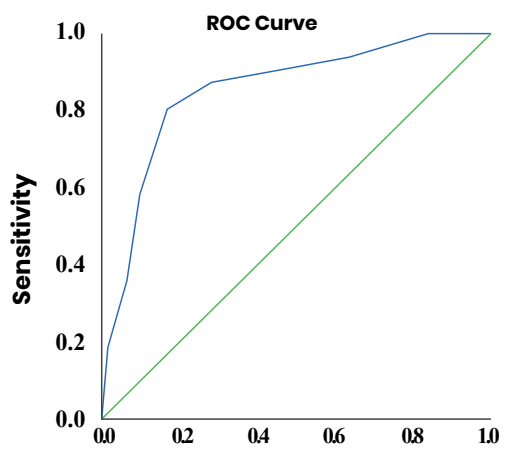

Figure - 7: Presence / absence of significant CAD in those with $\leq 3$ vs $>3$ risk fctors

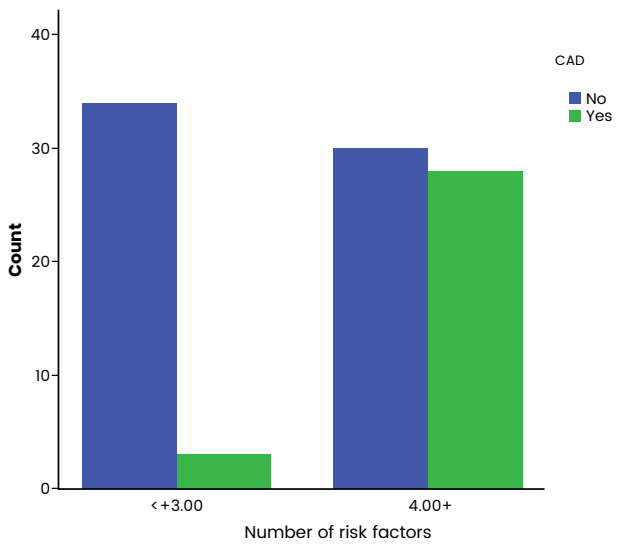

Figure - 8: Predictors of CAD in HFrEF

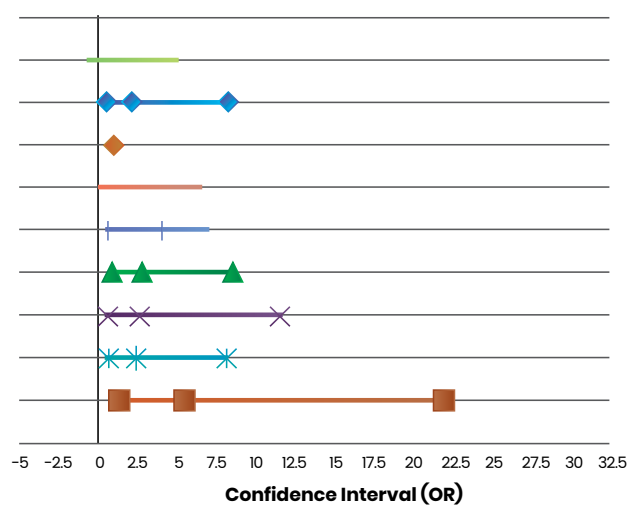

\section{Study limitations}

Relative to other previous large studies, our sample size was small and patients were enrolled from a single center, hence also subjected to referral bias. However, the current prospective design with coronary angiography is a merit. We enrolled only on patients with HFrEF and excluded patients with $\mathrm{HFmEF} / \mathrm{HFpEF}^{21}$. Finally, our study was limited by the fact that moderate lesions were not further analyzed with functional flow reserve (FFR) or intravascular coronary imaging. This may have led to underestimation of the prevalence of CAD. However, the identification of CAD led to the initiation of suitable medical treatment (antiplatelet therapy, statins) that has previously demonstrated its beneficial effect on outcomes. ${ }^{22,23}$

\section{Conclusions}

We determined the prevalence and characteristics of CAD in patients with HFrEF in a prospective study and the use, for the first time, of a systematic coronary angiography approach. In our study, otherwise unexplained HFrEF showed 33\% significant CAD, which was higher than rates reported previously ${ }^{8}$. Further studies are needed to evaluate systematic angiography in $\mathrm{HFmEF} / \mathrm{HFpEF}$, and whether this approach is cost- effective and revascularization improves morbidity or mortality.

\section{Acknowledgements}

We would like to acknowledge Dr Binay Kumar Rauniyar, Dr Deepak Limbu, Dr Amrit Bogati, Dr Sachin Dungel and Dr Laksheshwar Pradhan for siginificant contribution towards recruitment of cases for the present study.

\section{Conflict of Interest: None}

\section{References}

1. Miqdhaadh Shareef MBK, Roshan Raut, Anish Hirachan, et al. Etiology of heart failure in the emergency department of a tertiary cardiac centre of Nepal. Nepalese Heart Journal. 2017;14(2):1-4. https://doi.org/10.3126/njh.v14i2.18494

2. Yancy CW, Jessup M, Bozkurt B, et al. 2013 ACCF/AHA guideline for the management of heart failure: a report of the American College of Cardiology Foundation/American Heart Association Task Force on Practice Guidelines. J Am Coll Cardiol. 2013;62(16):e147-239.

3. Blair JE, Zannad F, Konstam MA, et al. Continental differences in clinical characteristics, management, and outcomes in patients hospitalized with worsening heart failure results from the EVEREST (Efficacy of Vasopressin Antagonism in Heart Failure: Outcome Study with Tolvaptan) program. J Am Coll Cardiol. 2008;52(20):1640-8. https://doi.org/10.1016/j.gheart.2012.10.004

4. Moran AE, Oliver JT, Mirzaie M, et al. Assessing the Global Burden of Ischemic Heart Disease: Part 1: Methods for a Systematic Review of the Global Epidemiology of Ischemic Heart Disease in 1990 and 2010. Glob Heart. 2012;7(4):31529. https://doi.org/10.1016/j.gheart.2012.10.004

5. McMurray JJ, Adamopoulos S, Anker SD, et al. ESC Guidelines for the diagnosis and treatment of acute and 
chronic heart failure 2012: The Task Force for the Diagnosis and Treatment of Acute and Chronic Heart Failure 2012 of the European Society of Cardiology. Developed in collaboration with the Heart Failure Association (HFA) of the ESC. Eur Heart J. 2012;33(14):1787-847.

6. Scanlon PJ, Faxon DP, Audet AM, et al. ACC/AHA guidelines for coronary angiography. A report of the American College of Cardiology/American Heart Association Task Force on practice guidelines (Committee on Coronary Angiography). Developed in collaboration with the Society for Cardiac Angiography and Interventions. J Am Coll Cardiol. 1999;33(6): 1756-824. https://doi.org/10.1016/S0735-1097(99)00126-6

7. Pitts WR, Lange RA, Hillis LD, et al. Coronary arterial anatomy in patients with left ventricular systolic dysfunction without chest pain or previous myocardial infarction. Am J Cardiol. 1998;82(12):1530-1, A7.

https://doi.org/10.1016/S0002-9149(98)00700-0

8. Felker GM, Thompson RE, Hare JM, et al. Underlying causes and long-term survival in patients with initially unexplained cardiomyopathy. N Engl J Med. 2000;342(15):1077-84. https://doi.org/10.1056/NEJM200004133421502

9. Allman KC, Shaw LJ, Hachamovitch R, Udelson JE. Myocardial viability testing and impact of revascularization on prognosis in patients with coronary artery disease and left ventricular dysfunction: a meta-analysis. J Am Coll Cardiol. 2002;39(7):1151-8. https://doi.org/10.1016/S0735-1097(02)01726-6

10. Repetto A, Dal Bello B, Pasotti M, et al. Coronary atherosclerosis in end-stage idiopathic dilated cardiomyopathy: an innocent bystander? Eur Heart J. 2005;26(15):1519-27. https://doi.org/10.1093/eurheartj/ehi342

11. Frustaci A, Chimenti C, Maseri A. Global biventricular dysfunction in patients with asymptomatic coronary artery disease may be caused by myocarditis. Circulation. 1999;99(10):1295-9.

https://doi.org/10.1161/01.CIR.99.10.1295

12. Shrestha UK, Alurkar VM, Baniya R, et al. Profiles of heart failure in the western region of Nepal: prognostic implications of the MELD-XI score. Internal Medicine Inside. 2015;3(1). https://doi.org/10.7243/2052-6954-3-1

13. Dubey L, Sharma SK, Chaurasia AK. Clinical profile of patients hospitalized with heart failure in Bharatpur, Nepal. J Cardiovasc Thorac Res. 2012;4(4):103-5.

14. McKee PA, Castelli WP, McNamara PM, Kannel WB. The natural history of congestive heart failure: the Framingham study. N Engl J Med. 1971;285(26):1441-6. https://doi.org/10.1056/NEJM197112232852601

15. Lang RM, Badano LP, Mor-Avi V, et al. Recommendations for cardiac chamber quantification by echocardiography in adults: an update from the American Society of Echocardiography and the European Association of Cardiovascular Imaging. J Am Soc Echocardiogr. 2015;28(1):1-39 e14. https://doi.org/10.1016/j.echo.2014.10.003

16. Doukky R, Shih MJ, Rahaby M, et al. A simple validated clinical tool to predict the absence of coronary artery disease in patients with systolic heart failure of unclear etiology. Am J Cardiol. 2013;112(8):1165-70. https://doi.org/10.1016/j.amjcard.2013.05.078

17. Hwang SJ, Melenovsky V, Borlaug BA. Implications of coronary artery disease in heart failure with preserved ejection fraction. J Am Coll Cardiol. 2014;63(25 Pt A):2817-27. https://doi.org/10.1016/j.jacc.2014.03.034

18. Ponikowski P, Voors AA, Anker SD, et al. 2016 ESC Guidelines for the diagnosis and treatment of acute and chronic heart failure: The Task Force for the diagnosis and treatment of acute and chronic heart failure of the European Society of Cardiology (ESC)Developed with the special contribution of the Heart Failure Association (HFA) of the ESC. Eur Heart J. 2016;37(27):2129-200. https://doi.org/10.1093/eurheartj/ehw128

19. Ramee S, Anwaruddin S, Kumar G, et al. The Rationale for Performance of Coronary Angiography and Stenting Before Transcatheter Aortic Valve Replacement: From the Interventional Section Leadership Council of the American College of Cardiology. JACC Cardiovasc Interv. 2016;9(23):2371-5. https://doi.org/10.1016/j.jcin.2016.09.024

20. Doshi D, Ben-Yehuda O, Bonafede M, et al. Underutilization of Coronary Artery Disease Testing Among Patients Hospitalized With New-Onset Heart Failure. J Am Coll Cardiol. 2016;68(5):450-8.

https://doi.org/10.1016/j.jacc.2016.05.060

21. Trevisan L, Cautela J, Resseguier N, et al. Prevalence and characteristics of coronary artery disease in heart failure with preserved and mid-range ejection fractions: A systematic angiography approach. Arch Cardiovasc Dis. 2018;111(2):109-18.

https://doi.org/10.1016/j.acvd.2017.05.006

22. Bangalore S, Pursnani S, Kumar S, Bagos PG. Percutaneous coronary intervention versus optimal medical therapy for prevention of spontaneous myocardial infarction in subjects with stable ischemic heart disease. Circulation. 2013;127(7):769-81.

https://doi.org/10.1161/CIRCULATIONAHA.112.131961

23. Shepherd J, Barter P, Carmena R, et al. Effect of lowering LDL cholesterol substantially below currently recommended levels in patients with coronary heart disease and diabetes: the Treating to New Targets (TNT) study. Diabetes Care. 2006;29(6):1220-6. https://doi.org/10.2337/dc05-2465 